\title{
A Pediatric Case of Acute Generalized Pustular Eruption without Streptococcal Infection
}

\author{
Nobuko Tabata Hideka Yoshizawa \\ Department of Dermatology, Japanese Red Cross Sendai Hospital, Sendai, Japan
}

\section{Keywords}

Pustulosis acuta generalisata - Acute generalized exanthematous pustulosis · Generalized pustular psoriasis $\cdot$ Streptococcal infection

\begin{abstract}
Generalized pustular lesions characterized by acute onset with fever occur in pustulosis acuta generalisata, acute generalized exanthematous pustulosis, and generalized pustular psoriasis. In the present report, we describe a pediatric case of generalized pustular eruption that was not completely consistent with clinical features. Our patient had no evidence of a poststreptococcal infection. We observed scattered symmetric eruption of discrete pustules with an inflammatory halo on normal skin. The eruption was absent on her palms and soles of the feet. To the best of our knowledge, there are no reports in the English literature of cases with clinical features similar to those of our patient.

(C) 2016 The Author(s) Published by S. Karger AG, Basel
\end{abstract}

\section{Introduction}

The differential diagnosis of generalized pustular eruptions with acute onset includes pustulosis acuta generalisata (PAG), acute generalized exanthematous pustulosis (AGEP), and generalized pustular psoriasis (GPP). PAG is characterized by scattered pustules with a red halo on normal skin with initial involvement of acral areas [1]. Streptococcal infections precede the appearance of PAG. AGEP is most often caused by drug intake. An erythematous 
and edematous eruption usually appears in the intertriginous areas or on the face and then disseminates to other skin areas. Soon thereafter, hundreds of confluent, pin-sized, nonfollicular, sterile pustules arise on a diffuse, generalized erythema [2]. Histologically, PAG and AGEP show intra-epidermal pustule formation and cannot be differentiated. GPP can be triggered by upper respiratory tract infections. Most patients with GPP have a previous history of psoriasis and the course is recurrent. The histological features of GPP are subcorneal pustules and psoriasiform acanthosis, which are diagnostic [3]. Our patient's findings were suggestive of PAG in that she showed discrete pustules with an inflammatory halo on normal skin. However, there were no eruptions on acral areas and an elevated anti-streptolysin 0 (ASO) titer was not observed.

\section{Case Report}

A 14-month-old girl was admitted to our hospital with a 5-day history of a generalized pustular eruption and a 2-day history of fever. She had a cough, yellowish rhinorrhea and limited erythema below her nose 3 weeks earlier. During the following weeks, increasing erythema without pustules developed around both eyes and then it gradually improved. However, 1 week before admission, fine pustules and erythema appeared on her trunk and lower extremities. She received tipepidine hibenzate $(15 \mathrm{mg} / \mathrm{d}), 3$-(carboxymethyl)-Lcysteine $(300 \mathrm{mg} / \mathrm{d})$, d-chlorpheniramine maleate $(1.2 \mathrm{mg} / \mathrm{d})$ and procaterol hydrochloride hydrate $(25 \mu \mathrm{g} / \mathrm{d})$ after onset of pustules (fig. 1). Five days before admission, dexamethasone $(0.06 \mathrm{mg} / \mathrm{kg} / \mathrm{d})$, hydroxyzine pamoate $(20 \mathrm{mg} / \mathrm{d})$ and beclomethasone dipropionate ointment were initiated but the eruption spread to almost her whole body and she developed a high fever. On examination, she had a temperature of $39.4^{\circ} \mathrm{C}$. Her face, trunk, and extremities had numerous, 2-5 mm diameter pustules with a red halo (fig. $2 \mathrm{a}, \mathrm{b}$ ). These pustules were absent on the inner aspects of her extremities, palms and soles of the feet, axillae, and inguinal regions (fig. 2c-e). Laboratory results showed a white blood cell count of $2.3 \times$ $10^{4} \mu \mathrm{l}$ and an erythrocyte sedimentation rate of $2 \mathrm{~mm} / \mathrm{h}$. Liver function tests, and urea, creatinine and serum calcium levels were within the normal limits. Serological tests for EpsteinBarr virus, cytomegalovirus, and herpes simplex virus were negative. The C-reactive protein level was $3.9 \mathrm{mg} / \mathrm{dl}$. Nasal swab cultures revealed growth of methicillin-susceptible Staphylococcus aureus and Moraxella catarrhalis. ASO titers were negative. A skin lesion biopsy from the right forearm (fig. $2 \mathrm{~b}$ ) showed a single intra-epidermal neutrophilic pustule with surrounding spongiosis (fig. 3a, b) and mild inflammatory infiltration mainly consisting of mononuclear cells in the dermis (fig. 3c). No evidence of vasculitis was seen.

The patient was initially treated with piperacillin sodium $(1,050 \mathrm{mg} / \mathrm{d})$ and ceftriaxone sodium hydrate $(500 \mathrm{mg} / \mathrm{d})$. On day 2 of hospitalization, she had a fever of $40.2^{\circ} \mathrm{C}$. Intravenous prednisone $(2 \mathrm{mg} / \mathrm{kg} / \mathrm{d})$ was added. On day 3 , she responded immediately with improvement of the fever and erythema around the pustules. All of the pustules had resolved within 14 days of their onset (fig. 1). An elevation in the ASO titer was not observed. No recurrence has been observed after 3 years of follow-up.

\section{Discussion}

The first patient with PAG was reported by Tan [4] under the term 'acute generalized pustular bacterid'. The term PAG was first used by Braun-Falco et al. [1]. Cutaneous manifes- 
tations of PAG are characterized by a scattered symmetric eruption of sterile pustules with an inflammatory halo on normal skin. The pustules start on the palms and soles and then extend to involve the limbs and the trunk. Streptococcal infections usually precede the appearance of PAG. Histology shows spongiotic subcorneal and/or intra-epidermal pustules and leukocytoclastic vasculitis is occasionally observed. The course of PAG is self-limiting and the pustules usually resolve within 1-2 weeks. In addition to these findings, Patrizi et al. [5] reported that a diagnosis of PAG was supported by the following features: absence of personal and family history of psoriasis; resolution without relapses; a personal history negative for drug intake, and an elevated ASO titer.

In our case, the pustules were isolated and were not arising on a widespread erythema. The histopathological findings showed subcorneal collection of many neutrophils in the epidermis. All of the pustules resolved within 2 weeks and did not recur. There was no history of psoriasis or drug intake before the appearance of pustules. Based on these features, we considered that our patient was most likely to have PAG among the group of sterile generalized pustular eruptions. However, the absence of pustules on the palms and soles, and the absence of a streptococcal infection are not in agreement with previous reports on PAG [57]. To the best of our knowledge, there are no reports in the English literature of cases with clinical features similar to those of our patient. The findings from our case suggest that acute generalized pustular eruption similar to PAG might be caused by infections, including viral infections that were not examined, except for streptococcal infection. In such cases, the distribution of pustules might be different from that in PAG. We hope that this report will lead to an accumulation of reports of various acute, sterile, generalized pustular eruptions.

\section{Statement of Ethics}

Informed consent for publishing the case was obtained from the parents of the patient.

\section{Disclosure Statement}

The authors declare no conflicts of interest.

\section{References}

1 Braun-Falco 0, Luderschmidt C, Maciejewski W, Scherer R: Generalized acute pustulosis. An unusual presentation of leukocytoclastic vasculitis (in German). Hautarzt 1978;29:371-377.

2 Roujeau JC, Bioulac-Sage P, Bourseau C, Guillaume JC, Bernard P, Lok C, Plantin P, Claudy A, Delavierre C, Vaillant L, Wechsler J, Danan G, Bénichou C, Beylot C: Acute generalized exanthematous pustulosis. Analysis of 63 cases. Arch Dermatol 1991;127:1333-1338.

-3 Baker H, Ryan TJ: Generalized pustular psoriasis. A clinical and epidemiological study of 104 cases. Br J Dermatol 1968;80:771-793.

-4 Tan RSH: Acute generalized pustular bacterid. An unusual manifestation of leukocytoclastic vasculitis. Br J Dermatol 1974;91:209-215.

-5 Patrizi A, Savoia F, Giacomini F, Neri I, Ricci G: Diffuse acute pustular eruption after streptococcal infection-a new instance of pustulosis acute generalisata. Pediatr Dermatol 2007;24:272-276. Auer-Grumbach P, Pfaffenthaler E, Soyer HP: Pustulosis acuta genefalisata is a post-streptococcal disease and is distinct from acute generalized exanthematous pustulosis. Br J Dermatol 1995;133:135139.

7 Eren M, Fabri M, Krieg T, FRCP, Eming SA: Pustulosis acuta generalisata with joint involvement in an HLA-A2-and KLA-B35-positive patient. J Am Acad Dermatol 2008;58:1056-1058. 


\section{Case Reports in \\ Dermatology}

Case Rep Dermatol 2016;8:173-178

C 2016 The Author(s). Published by S. Karger AG, Base www.karger.com/cde

Tabata and Yoshizawa: A Pediatric Case of Acute Generalized Pustular Eruption without Streptococcal Infection

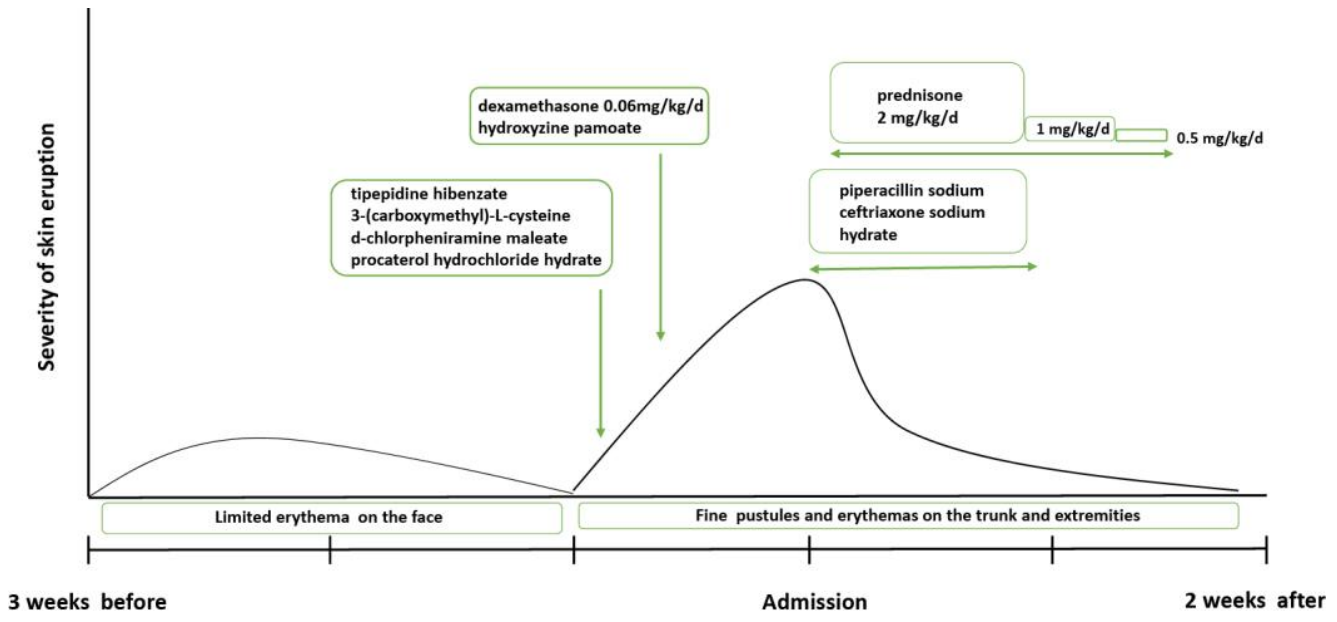

Fig. 1. Clinical course and treatments. 


\section{Case Reports in Dermatology}

\begin{tabular}{l|l}
\hline Case Rep Dermatol 2016;8:173-178 \\
\hline $10.1159 / 000446691$ & $\begin{array}{l}\text { C } 2016 \text { The Author(s). Published by S. Karger AG, Basel } \\
\text { www.karger.com/cde }\end{array}$ \\
\hline
\end{tabular}
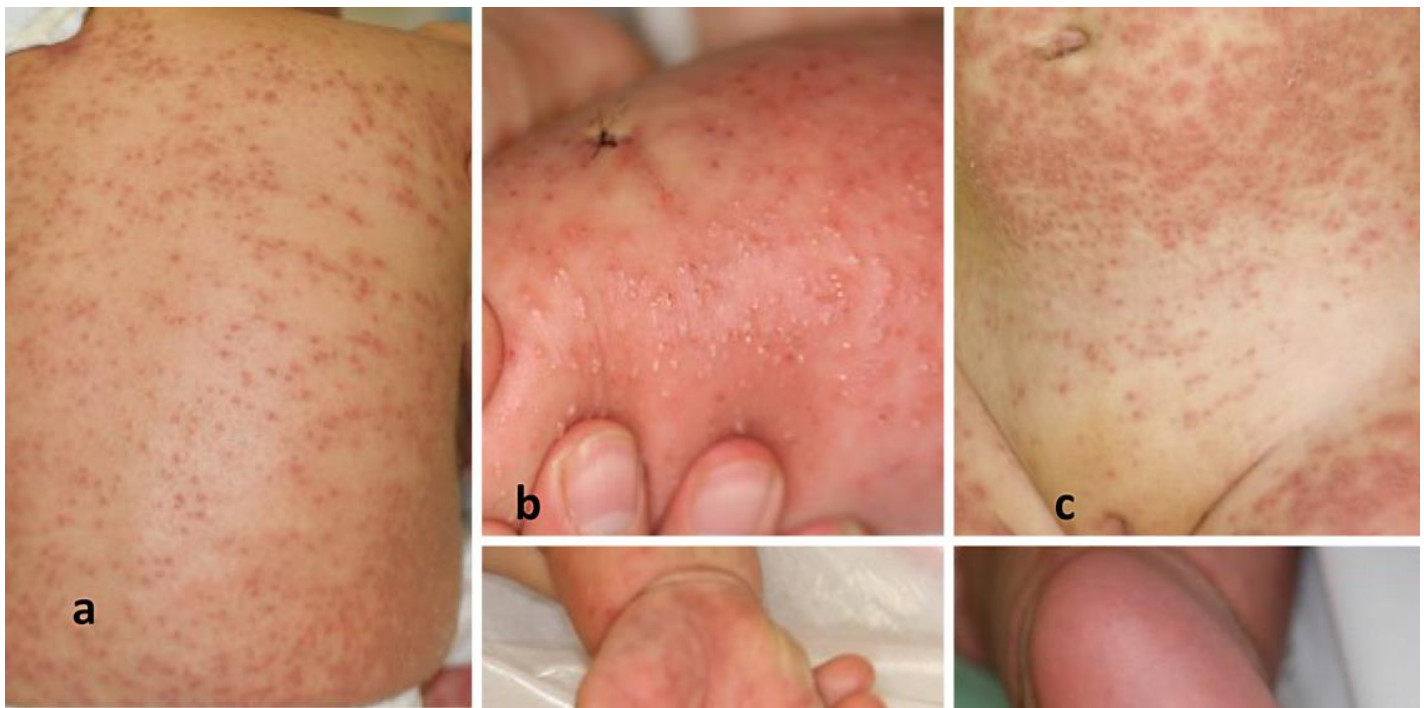

Tabata and Yoshizawa: A Pediatric Case of Acute Generalized Pustular Eruption without Streptococcal Infection
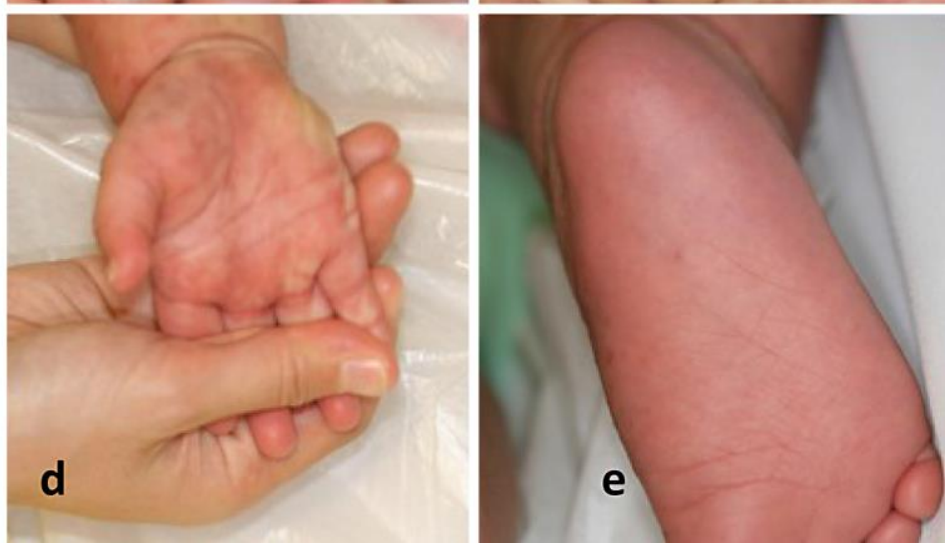

Fig. 2. Clinical features on admission. a-c Numerous pustules with a red halo on the trunk and on the forearms can be seen. c-e Pustules were not observed in the intertriginous and acral areas. 


\section{Case Reports in \\ Dermatology}

Case Rep Dermatol 2016;8:173-178 www.karger.com/cde

Tabata and Yoshizawa: A Pediatric Case of Acute Generalized Pustular Eruption without Streptococcal Infection
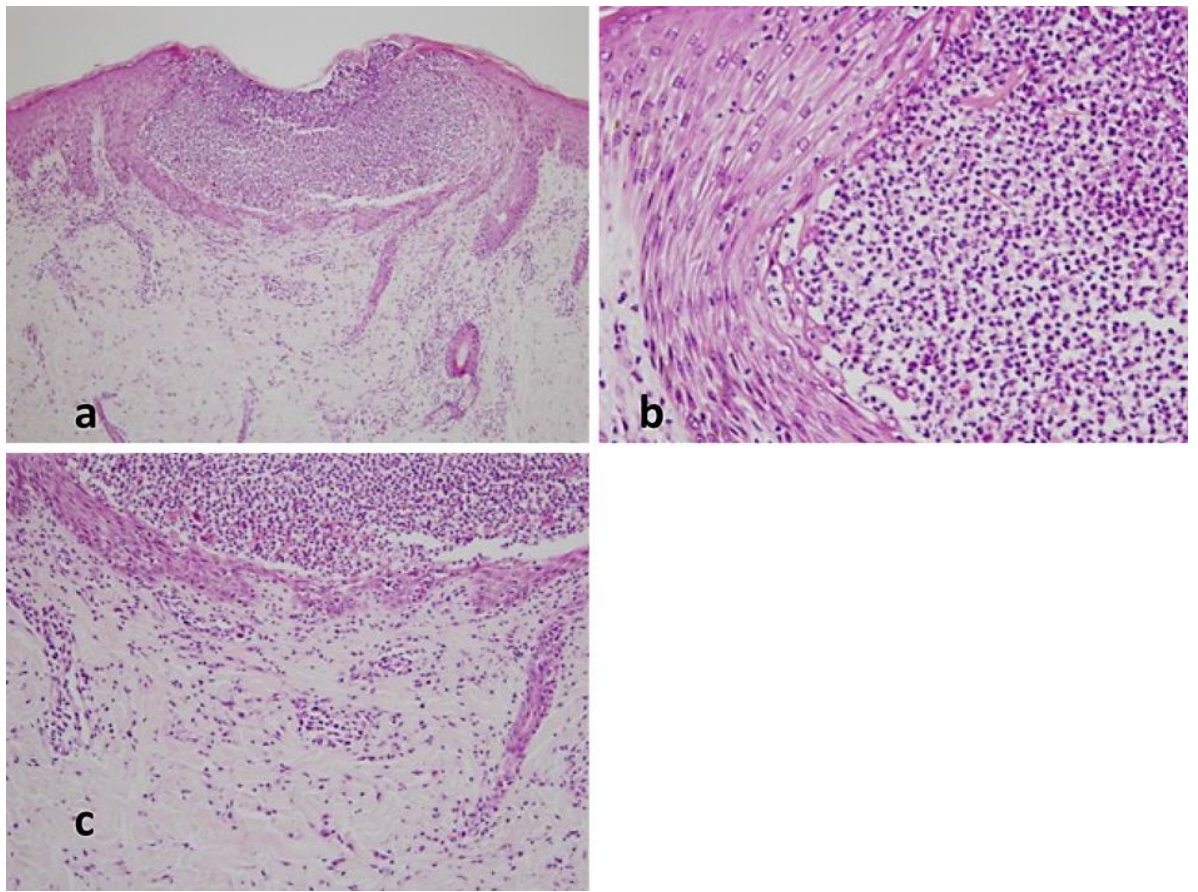

Fig. 3. Histopathological findings. a, b A skin biopsy shows a single intra-epidermal neutrophilic pustule (original magnification $\mathbf{a} \times 50, \mathbf{b} \times 400$ ). c Mild inflammatory infiltration in the dermis. There was no evidence of vasculitis $(c \times 200)$. 